\title{
Function of the left ventricular myocardium without blood during dextran perfusion
}

\author{
PANAGIOTIS C. PETROPOULOS
}

From the Department of Surgery of the Wilhelmina Hospital, University of Amsterdam, The Netherlands

The possibility of maintaining organs and tissues in an active state by substituting for the blood through the femoral vessels oxygenated macrodex at 3 atmospheres absolute (ATA) has been demonstrated by the pioneer work of Boerema et al. (1960) and Boerema (1961). When, during hyperbaric oxygenation, the level of haemoglobin was reduced to $0.4 \mathrm{~g} . / 100 \mathrm{ml}$. (Sahli) the animals were kept during 15 minutes at this low level. In previous communications we reported that the perfusion of dextran of 40,000 molecular weight (rheomacrodex) at a rate of $25 \mathrm{ml} . / \mathrm{min}$. for 30 minutes could maintain the normal heart beat and pressures as long as severe hypervolaemia due to hyperfusion or anaemia from exsanguination did not occur (Petropoulos, 1963 ; Petropoulos and Meijne, 1964). Such perfusions have been reported in the literature in the isolated heart (Salisbury, Cross, and Rieben, 1962) but not in the beating heart which is maintaining the work load of the circulation. The effects of coronary perfusion could perhaps be better evaluated by the Boerema blood exchange technique. During hyperbaric oxygenation, by perfusing oxygenated rheomacrodex at 3 ATA simultaneously to the two main branches of the left coronary artery, and meanwhile extracting blood by phlebotomy in an amount equal to the perfused rheomacrodex, it may be possible to avoid the undesirable results of hypervolaemia or anaemia.

The purpose of our investigations was to study the effects of perfusion of oxygenated low-molecular dextran at 3 ATA, first into the circumflex coronary artery and secondly into both main branches of the left coronary artery simultaneously.

\section{PERFUSION OF THE CIRCUMFLEX CORONARY ARTERY}

METHODs Five unselected dogs weighing from 10.3 to $12.5 \mathrm{~kg}$. were used. Anaesthesia was induced and maintained with intravenous nembutal ( $25 \mathrm{mg}$. $/ \mathrm{kg}$.). Cyclic positive pressure insufflation of the lungs with $100 \%$ oxygen was maintained and the thorax was opened through the fifth left intercostal space. The descending aorta and inferior vena cava were cannulated through the femoral artery and vein, the cannulae being connected to an electric manometer from which pressures were continuously obtained. The standard E.C.G. leads and E.E.G. were recorded. It is important at this stage to note the coronary artery variations of the hearts. The region of the angle between the circumflex and anterior descending coronary arteries was vascularized frcm a branch arising from the anterior descending coronary artery in three dogs and frcm the circumflex coronary artery in two dogs. The branches of the anterior descending coronary artery were predominantly distrituted in the left ventricle (type $A$ ) in four dogs and in both left and right ventricles (type B) in one dog (Meesman, 1958). The circumflex coronary artery was prepared for about $3 \mathrm{~cm}$. from its origin.

At this stage the pressure in the caisson was raised to 3 ATA (Boerema, 1961). The circumflex coronary. artery was then ligated as near as possible to its origin,. and the distal portion was cannulated with a $1.65-\mathrm{mm}$. nylon cannula with a terminal hole. The catheter was. inserted into the lumen of the artery about $2 \mathrm{~cm}$. distal to. its origin. The tip of the catheter was secured scme: millimetres distal to the first auricular branch, the origin of which was thus occluded by the side wall of the catheter. Between the level of the ligature of the circumflex coronary artery and the tip of the catheter, mediumsized ventricular branches were occluded in only two dogs. The catheter was connected to a strain gauge and backpressures were recorded. These were between 20/8 and $44 / 22 \mathrm{~mm}$. Hg. A solution of $6 \%$ low-molecular dextran in saline (rheomacrodex 45,000 molecular weight) at $37^{\circ} \mathrm{C}$., bubbled one hour before and during perfusion with oxygen through a porous aquarium stone at the rate of 2 litres/min., was then perfused into the artery (Fig. 1 A). To each litre of rheomacrodex, salts were added to form a solution similar to Ringer's solution (Boerema et al., 1960). The perfusion rate was initially $4 \mathrm{ml} . / \mathrm{min}$. and this was gradually increased to $25 \mathrm{ml}$. $/ \mathrm{min}$. within two minutes. Phlebotomy was performed at the beginning of the perfusion.

RESULTS After coronary occlusion and during cannulation, ventricular fibrillation occurred in two. dogs, but by instituting heart massage and defibrillation restoration of the heart beat was easily achieved. Some seconds to one minute after circumflex occlusion, the left lateral and posterior surface of the left. ventricle of all the animals became cyanotic. The 

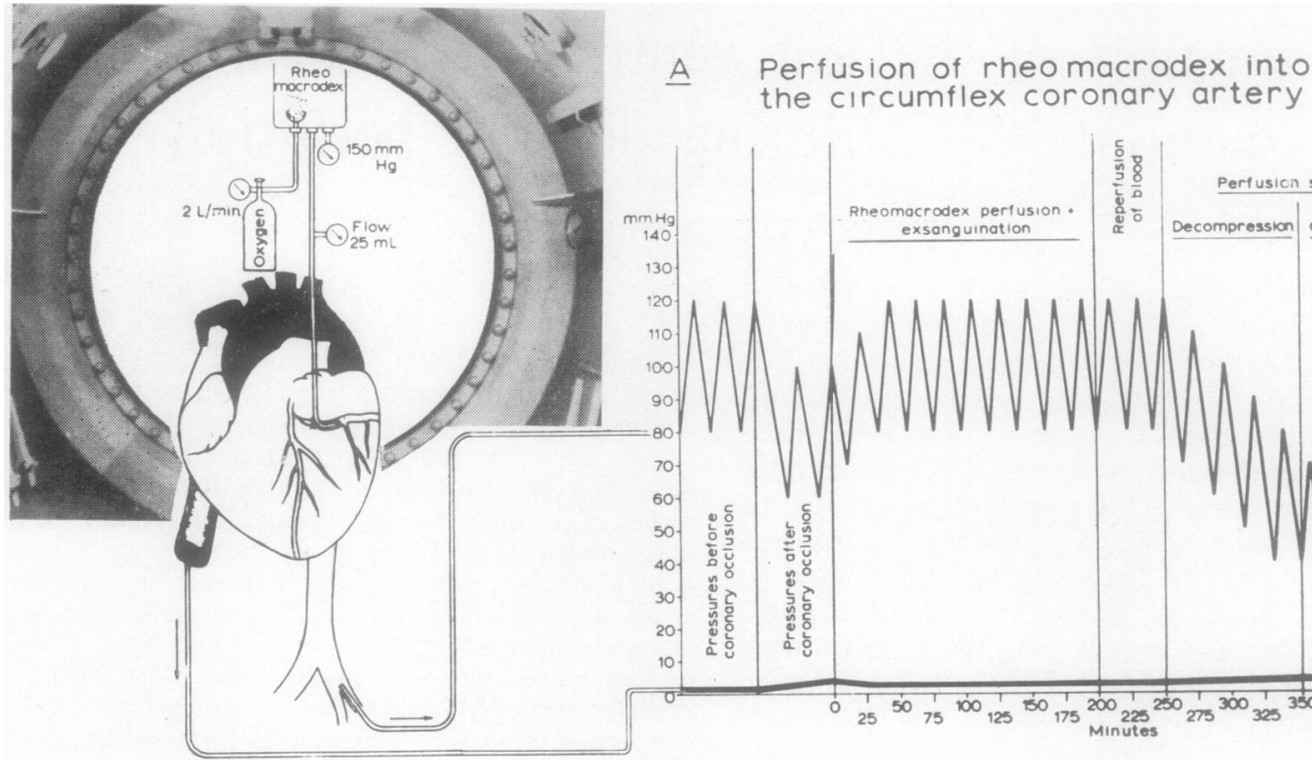


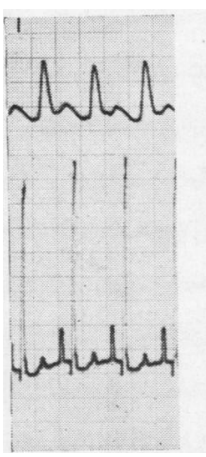

limits of this change of colour were well demarcated, although the extent of the cyanotic area was not the same. The E.C.G. showed alterations of the S-T segment, essentially in leads II and III with notching and other deviations of the QRS complexes as well as extrasystolic irregularities. The arterial pressure decreased by 5 to $20 \mathrm{~mm}$. Hg in three dogs, but the venous pressure did not change significantly. During perfusion with rheomacrodex the left border and posterior surface of the left ventricle became whitish. This white colour gradually invaded the limits of the area of the anterior descending coronary artery. After seven to 10 minutes the extrasystoles decreased and the ischaemic E.C.G. changes regressed (Fig. 2). Alterations of the mode of contraction of the circumflex myocardial area or systolic expansion was not observed, visually at least. The arterial and venous pressures were near the pre-occlusive levels (Fig. 1A).

The perfusion was continued for 200 minutes, during which $5,000 \mathrm{ml}$. of rheomacrodex was perfused. The haemoglobin of the extracted blood gradually decreased from initial values of 102 to $112 \mathrm{~g} . / 100 \mathrm{ml}$. (Sahli) to 5 and $2.5 \mathrm{~g} . / 100 \mathrm{ml}$. after 200 minutes' perfusion. The determination of alkali reserve showed before perfusion $p \mathrm{H}$ values ranging from 7.25 to 7.45 (measured with a Philips glass electrode), bicarbonate content 24.5 to $27 \mathrm{mEq}$./litre, and $\mathrm{PCO}_{2} 18.2$ to $19.5 \mathrm{~mm}$. $\mathrm{Hg}$. After 200 minutes' perfusion-exsanguination there was a steady decrease in $p \mathrm{H}$ from 6.68 to 7 . The bicarbonate was 17.6 to $19.2 \mathrm{mEq}$./litre and the $\mathrm{PCO}_{2}$ between 45 and $68 \mathrm{~mm}$. Hg.

The perfusion was then stopped and fresh arterial blood was re-perfused at the same rate for 40 to 50 minutes. Decompression was started and the perfusion was stopped. The arterial pressure decreased gradually and the ischaemic E.C.G. changes reappeared. After decompression the ventilation was continued with a mixture of $50 \%$ oxygen and room air. The arterial pressure was reduced to between $40 / 20$ and $80 / 60 \mathrm{~mm} . \mathrm{Hg}$, the venous pressure being slightly increased. The rectal temperature at the

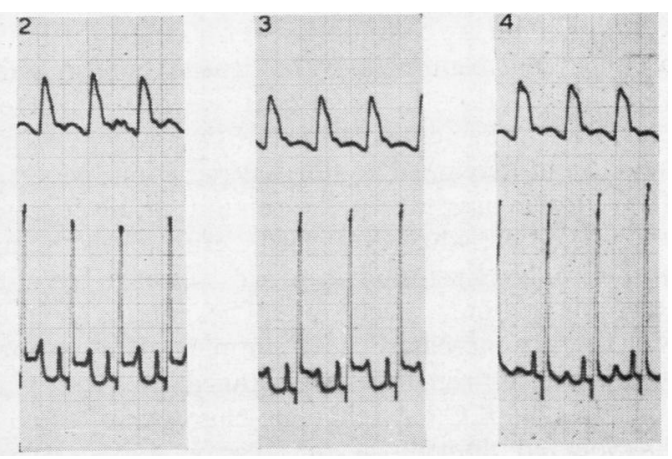

end of the perfusion was decreased by 1.5 to $2.7^{\circ} \mathrm{C}$. About one hour after decompression spontaneous respiration returned. Corneal and pupil reflexes reappeared. No cerebral ischaemia was revealed in the E.E.G. records. The animals were then sacrificed. The weight of the hearts was within predictable limits (t.errmann, 1925). Oedema of the perfused myocardial region was not found.

CONTROL EXPERIMENTS An increase of physically dissolved oxygen in the plasma and tissues during inhalation of $\mathrm{O}_{2}$ at 3 ATA is known to ensure satisfactory heart function in the majority of cases after circumflex coronary occlusion during hyperbaric oxygenation (Petropoulos, 1964; Smith and Lawson, 1962). In order to compare the results of long-term rheomacrodex perfusion in our experiments with those after simple coronary occlusion during hyperbaric oxygenation the following control experiments were performed.

Twenty-five unselected young dogs weighing $12 \cdot 2$ to $16.5 \mathrm{~kg}$. were used. Anaesthesia was induced and maintained as before. Ventilation was performed with $100 \%$ oxygen. The angle of bifurcation of the left coronary artery was vascularized from a branch arising from the anterior descending coronary artery in 17 dogs and from the circumflex coronary artery in eight dogs. The distribution of the branches of the anterior descending coronary artery was of type A in 17 dogs and of type B in eight (Meesmann, 1958). When the pressure in the caisson was raised to 3 ATA, the circumflex artery was occluded and cannulated as before. Coronary backpressures, arterial and venous pressures, E.C.G. and E.E.G. were recorded. In order to avoid the usual drop in temperature of the left ventricle after circumflex coronary artery occlusion, the chest was temporarily closed, the catheter of the cannulated artery remaining in place. The hyperbaric oxygenation continued for two hours. One hour after decompression the animals were sacrificed. 
RESULTS During cannulation ventricular fibrillation occurred in five animals. By instituting heart massage and defibrillation the heart beat was restored. However, the cardiac contractions of two dogs remained weak, and irreversible fibrillation soon occurred. The arterial pressure of the remaining 23 dogs was unchanged or, when decreased, returned to the preocclusive level within 10 to 28 minutes from the start of coronary occlusion. The venous pressure was slightly increased in all animals. The coronary backpressures remained unchanged or slightly increased. The E.C.G. ischaemic changes regressed or disappeared. During decompression and one hour later insignificant haemodynamic changes occurred. All animals survived until they were sacrificed.

DISCUSSION In our experimental and control dogs during hyperbaric oxygenation, perfusion of the circumflex coronary artery with low molecular dextran or simple occlusion of the artery could maintain an apparently normal heart beat and pressures. When the perfusion was stopped during decompression the arterial pressure significantly decreased. On the other hand, in the control dogs the pressures remained unchanged or slightly decreased. Although in the control dogs the percentage of recurrence of fibrillation and mortality during hyperbaric oxygenation was $8 \%$, these results cannot be compared with those of perfusion because a much smaller number of experiments was undertaken.

SUMMARY Perfusion of the circumflex coronary artery with oxygenated rheomacrodex at 3 ATA at a rate which gradually increased to $25 \mathrm{ml} . / \mathrm{min}$. could maintain the heart beat and pressures stable during the 200 minutes' perfusion. After re-perfusion of blood, during gradual decompression, and one hour later, the animals survived although the arterial pressure significantly decreased. Simple occlusion of the circumflex coronary artery during hyperbaric oxygenation had similar results with the difference that during and after decompression the pressures remained more stable than those of the perfusion group.

SIMULTANEOUS PERFUSION OF BOTH MAIN BRANCHES OF THE LEFT CORONARY ARTERY

METHOD; Eight unselected dogs were used, weighing 13.5 to $15 \mathrm{~kg}$. Anaesthesia was induced and maintained as before, and $100 \%$ oxygen was inhaled. Aortic and venal caval pressures, E.C.G. and E.E.G. were continuously recorded. The angle of bifurcation of the left coronary artery was vascularized from branches arising from the circumflex coronary artery in three dogs and from the anterior descending coronary artery in the remaining five. The distribution of the branches of the anterior descending coronary artery was of type $A$ in $\underline{\underline{G}}$ seven dogs and of type B in one (Meesmann, 1958). The $\frac{\bar{c}}{7}$ circumflex and anterior descending coronary arteries $\mathbb{\nabla}$ were prepared for about $3 \mathrm{~cm}$. from their origin. At this stage the pressure in the caisson was raised to 3 ATA. $\infty$ The circumflex coronary artery was occluded, cannulated $\overrightarrow{0}$ and perfused with rheomacrodex as before in three dogs and with arterial blood in the remaining five. After five $\vec{\omega}$ minutes the perfusion flow was increased to $50 \mathrm{ml} / \mathrm{min}$. and the anterior descending coronary artery was occluded $\underset{x}{x}$ $1 \mathrm{~cm}$. distal to its origin and cannulated with a similar technique. The tip of the catheter was secured some millimetres distal to the first left main branch of the artery. The septal artery was identified and care was taken not to occlude it. Perfusion was then started with 오 oxygenated rheomacrodex containing the same salts as before at a rate of $25 \mathrm{ml}$./min. (Fig. 1 B). Phlebotomy was performed at the beginning of perfusion. Care was taken to extract blood in amounts equal to the perfused rheomacrodex each minute.

RESULTS After circumflex coronary artery occlusion and cannulation ventricular fibrillation occurred in one dog. The perfusion was then stopped. During heart massage and defibrillation the normal heart beat was easily restored. Five to 11 minutes after rheomacrodex perfusion the arterial and venous pressures had reached about the same level as the pre-occlusive level. The increase of the perfusion flow to $50 \mathrm{ml} . / \mathrm{min}$. was well tolerated in all animals. The heart beat and pressures remained unchanged. The ischaemic E.C.G. changes regressed. During occlusion and cannulation of the anterior descending coronary arteries in the first three dogs ventricular fibrillation occurred. The perfusion was then stopped because from previous experience we knew that if perfusion of rheomacrodex was continued during defibrillation this would result in heart oedema (Petropoulos and Meijne, 1964). By instituting heart massage and defibrillation restoration of the heart beat was not possible.

Fresh heparinized arterial blood was then perfused $N$ at the same flow rate. After four to eight minutes $N$ perfusion and defibrillation efforts the heart beat was restored but the arterial pressure remained at a low level between $40 / 20$ and $55 / 30 \mathrm{~mm}$. Hg. Rheomacrodex perfusion to the anterior descending coronary artery was then begun. Ventricular fibrilla- $\mathbb{D}$ tion recurred within two to three minutes. No further attempt at defibrillation was made. In the remaining five dogs, after five minutes' blood perfusion into the circumflex coronary artery at the same rates, the perfusion was continued. Five minutes later the flow rate was increased to $50 \mathrm{ml}$./ 2 min. and the anterior descending coronary artery was cannulated and rheomacrodex was perfused. 
After cannulation and during perfusion the arterial pressures decreased by 25 to $50 \mathrm{~mm}$. $\mathrm{Hg}$ and the ischaemic changes in the E.C.G. reappeared. The rheomacrodex perfusion was then changed to arterial blood perfusion for another 10 minutes. The pressures during blood perfusion remained at the same level, and the ischaemic changes in the E.C.G. persisted. The perfusion of the circumflex coronary artery was then changed to oxygenated rheomacrodex at the same rate. During perfusion the pressures (Fig. 1 B) and E.C.G. remained unchanged. The perfusion of the anterior descending coronary artery was also changed to rheomacrodex.

The perfusion of both arteries was continued in this way for 200 minutes, during which time the ischaemic E.C.G. changes persisted and the pressures remained at the same level. During perfusion the whole ventricular myocardium became whitish. This colour gradually invaded the right ventricle. After 200 minutes' perfusion with rheomacrodex the haemoglobin decreased from 3 to $1.6 \mathrm{~g} . / 100 \mathrm{ml}$. (Sahli). Before perfusion the alkali reserve values were pH 7.3 to 7.5 , bicarbonate 23.4 to $26.5 \mathrm{mEq}$./litre and $\mathrm{PCO}_{2} 20$ to $24.5 \mathrm{~mm}$. $\mathrm{Hg}$. After 200 minutes' perfusion the $p \mathrm{H}$ was 6.24 to 6.9 , bicarbonate 15.5 to $16.7 \mathrm{mEq}$./litre and the $\mathrm{PCO}_{2} 80$ to $102 \mathrm{~mm}$. $\mathrm{Hg}$. After rheomacrodex perfusion heparinized arterial blood was perfused into both arteries, during which time decompression was started. After 15 minutes' blood perfusion the haemoglobin and alkali reserve values returned to approximately the previous normal level. During blood perfusion the E.C.G. records remained unchanged. The rectal temperature after this long-term perfusion was decreased by $2 \cdot 3$ to $2 \cdot 9^{\circ} \mathrm{C}$. The animals were then sacrificed and the hearts were examined. Heart oedema was not observed. The septal artery was not found to be occluded by the intracoronary cannulae.

CONTROL EXPERIMENTS It is known that when both main branches of the left coronary artery are occluded during oxygenation at 3 ATA, ventricular fibrillation appears after some seconds (Petropoulos, 1964). Control experiments were necessary in order to study the limits of ischaemic tolerance of the left ventricular myocardium during oxygenation at 3 ATA, when the heart is bearing the work load of the circulation. For this purpose 10 unselected mongrel dogs weighing 12 to $17 \cdot 3 \mathrm{~kg}$. were used. The angle of bifurcation of the left coronary artery was vascularized from branches arising from the anterior descending coronary artery in six and from the circumflex coronary artery in the remaining four dogs. The distribution of the branches of the anterior descending coronary artery was of type A in seven dogs and of type $B$ in three. The animals were anąesthetized and ventilated with $100 \%$ oxygen as before. When the pressure in the caisson was raised to 3 ATA the circumflex artery was ligated at its origin. Thirty minutes later the anterior descending artery was gradually stenosed $1 \mathrm{~cm}$. below its origin with a screw occluding clamp. Every five minutes a stenosis of $0.2 \mathrm{~mm}$. of the lumen of the artery was performed. Pressures, E.E.G. and E.C.G. were recorded as before.

RESULTS After circumflex coronary artery occlusion ventricular fibrillation occurred in one dog. By instituting heart massage a spontaneous defibrillation was possible. The arterial pressures of all dogs three to 16 minutes after circumflex occlusion were equal to the pre-occlusive pressures. The venous pressure was slightly increased. The initial E.E.G. ischaemic post-occlusive changes regressed. During gradual stenosis of the anterior descending coronary artery the ischaemic changes in the E.C.G. reappeared when a stenosis of about $45 \%$ was performed. However, stenosis of $50 \%$ of the lumen of the artery (1 to $1.2 \mathrm{~mm}$.) was well tolerated. The venous pressures were further increased by 1 to $4 \mathrm{~mm}$. $\mathrm{Hg}$, and the arterial pressures slightly decreased by 10 to $25 \mathrm{~mm}$. Hg. At this stage one dog was decompressed and coronary arteriography was performed. Urokon $70 \%$ was injected through a polyethylene catheter inserted into the left subclavian artery, directed centrally to the base of the aorta (Fig. 3). In the remaining dogs, when a stenosis of 62 to $65 \%$ (about $1.5 \mathrm{~mm}$.) was performed, ventricular fibrillation occurred in three animals. In the remaining dogs, heart fibrillation occurred when a stenosis of 65 to $70 \%(1.5$ to $1.7 \mathrm{~mm}$. $)$ was performed.

DISCUSSION Perfusion of the left coronary artery with rheomacrodex could be more accurately performed if it were possible to use the left coronary ostium. Unfortunately the necessary radiographic assistance for such an insertion of the catheter is still not possible in the high-pressure chamber because of the dangers involved. On the other hand, such catheterization by open heart procedures was not desirable because the action of rheomacrodex was evaluated in hearts bearing the work load of the circulation.

Cannulating the main branches of the left coronary artery by the technique described, we could not avoid occlusion of the first side branches. The occlusion of such branches of the circumflex or the anterior descending coronary artery did not result in E.C.G. ischaemic changes or a decrease in arterial pressure. Occluding the branches of both arteries caused 


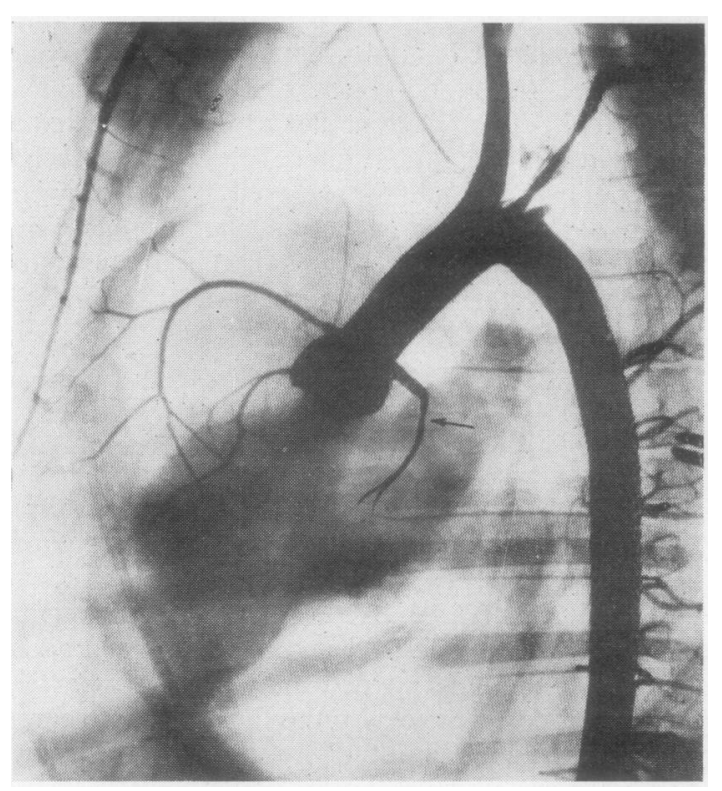

FIG. 3. Coronary arteriography via the left coronary artery. Anterior descending coronary artery stenosed $1 \mathrm{~cm}$. distal to its origin. Circumflex coronary artery not visualized.

ischaemia of a circumscribed area of the myocardium in the region of the angle of bifurcation of the left coronary artery which influenced the E.C.G. and arterial pressures during perfusion. These changes persisted even when arterial blood was perfused in both arteries. During these perfusions the inflow of blood to the septal artery was not disturbed.

Collateral blood from the right coronary artery or from extracardiac collaterals did not seem to enter into the vascular bed of the perfused area because (a) the extreme myocardial pallor in the perfused area indicated that blood was washed out of the coronary vessels, and $(b)$ when, during the 200 minutes' perfusion, a side branch of the circumflex artery was divided and its central segment ligated, blood never appeared in the backflow fluid.

It was remarkable that such a non-metabolic fluid as rheomacrodex containing dissolved oxygen could maintain the heart beat and pressures during this long-term perfusion. The left ventricular myocardial oxygen consumption is known to average $9.7 \mathrm{ml}$./ 100 g. muscle (Goodale, Lubin, Eckenhoff, Hafkenschiel, and Banfield, 1948). The left ventricular myocardial muscle averages $0.00315 \%$ of the body weight (Herrmann, 1925), and so had a weight of about $47 \mathrm{~g}$. in our dogs, which weighed $15 \mathrm{~kg}$. We may conclude that the oxygen content of the perfused oxygenated rheomacrodex at 3 ATA was sufficient to ensure the oxygenation of the perfused left ventricular myocardium: according to Campbell (1929), the oxygen in physical solution is about $6.9 \%$ at this pressure. It is known that by decreasing the haematocrit value the blood flow increases (Spencer, Merrill, Powers, and Bing, 1950). A maximal flow of blood would occur if there were no erythrocytes, and we think therefore that perfusion with rheomacrodex or blood at the same rates must show a better distribution in the case of rheomacrodex. However, in our experiments it was not possible to maintain the heart beat when both arteries were initially perfused with rheomacrodex. On the other hand, when blood was initially perfused in the circumflex artery the subsequent rheomacrodex perfusion of the anterior descending artery was well tolerated. Subsequently a change from blood to rheomacrodex perfusion in the circumflex artery was possible.

The mode of contraction of the perfused whitish myocardial area did not seem to be altered. This could be explained by its adequate oxygenation, and so we think that the energy of the heart muscle was obtained from the dissolved oxygen of the perfused rheomacrodex. The results of perfusions in isolated hearts cannot be compared with the experiments in which perfusion must supply the heart muscle with the energy necessary to maintain the work load of the circulation during the 200 minutes' perfusion. The longer maintenance of heart action during coronary perfusion with rheomacrodex, than when blood was substituted through the femoral artery by macrodex, may be attributed to the rheological properties of the former (Gelin, 1962). From the results of our experiments, we may conclude that by simultaneous perfusion of both main branches of the left coronary artery with oxygenated rheomacrodex at 3 ATA for 200 minutes it is possible for the left ventricular myocardium to maintain the work load of the circulation. These findings should let us consider the perfusion of oxygenated rheomacrodex to the coronary ostium in cases of aortic valve repairs, or operations for ascending aortic aneurysms, or even perfusions of the coronary arteries during coronary endarterectomies or anastomoses.

\section{SUMMARY}

During well-tolerated perfusions of oxygenated rheomacrodex at $3 \mathrm{ATA}$ at a rate of $50 \mathrm{ml} . / \mathrm{min}$. to the circumflex coronary artery, occlusion and cannulation of the anterior descending coronary artery 
resulted in ventricular fibrillation. When the circumflex coronary artery was perfused with arterial blood at the same flow rates, perfusion of the anterior descending artery with oxygenated rheomacrodex at a rate of $25 \mathrm{ml}$./min. was possible during which the perfusion of the circumflex artery could be changed to rheomacrodex. During 200 minutes' perfusionexsanguination the aortic pressure was decreased but ventricular fibrillation did not occur. Perfusion of both arteries with saturated blood at the same rate did not result in an increased pressure. In the control dogs occlusion of the circumflex coronary artery and simultaneous stenosis of the anterior descending artery to 65 to $70 \%$ resulted in ventricular fibrillation.

\section{REFERENCES}

Boerema, 1. (1961). An operating room with high atmospheric pressure. Surgery, 49, 291.

Meyne, N. G., Brummelkamp, W. K., Bouma, S., Mensch, M. H., Kamermans, F., Stern Hanf, M., and Van Aalderen, W. (1960). Life without blood. (A study of the influence of high atmospheric pressure and hypothermia on dilution of the blood.) $J$. cardiovasc. Surg. (Torino), 1, 133.
Campbell, J. A. (1929). Tissue oxygen tensicn and carbon monoxide poisoning. J. Physiol. (Lond.), 68, 81 .

Gelin, L. E. (1962). Rheologic disturbances and the use of low viscosity dextran in surgery. Rev. Surg., 19, 385.

Goodale, W. T., Lubin, M., Eckenhoff, J. E., Hafkenschiel, J. H. and Banfield, W. G. (1948). Coronary sinus catheterization for studying coronary blood flow and myocardial metabolism. Amer. J. Physiol., 152, 341.

Herrmann, G. R. (1925). Experimental heart disease. Amer. Heart J., $1,213$.

Meesmann, W. (1958). In Probleme der Coronardurchblutung, p. 120, ed. W. Lochner and E. Witzleb. Springer, Berlin-Göttingen.

Petropoulos, P. C. (1964). Influence of hyperbaric oxygenation on the haemodynamic changes and mortality after circumflex coronary artery occlusion. In Clinical Application of Hyperbaric Oxygen Proc. of the first int. Congr., Amsterdam, ed. I. Boerema, W. $\mathrm{H}$. Brummelkamp, and N. G. Meijne, p. 84. Elsevier, Amsterdam.

(1963). Effects on cardiac function during long-term perfusion of the coronary arteries with unsaturated blood or colloidal of the coronary arteries with unsaturated blood or
isotonic solutions. J. thorac. cardiovasc. Surg., 45, 460 .

- and Meijne, N. G. (1964). Cardiac function during perfusion of the circumflex coronary artery with venous blood, low molecular dextran or Tyrode solution. Amer. Heart J., $18,370$.

Salisbury, P. F., Cross, C. E., and Rieben, A. P. (1962). Intramyocardial pressure and strength of left ventricular contraction. Circulat. Res., 10, 608 .

Smith, G., and Lawson, D. L. (1962). The protective effect of inhalation of oxygen at two atmospheres absolute pressure in acute coronary artery occlusion. Surg. Gynec. Obstet., 114, 320.

Spencer, F. C., Merrill, D. L., Powers, S. R., and Bing, R. J. (1950). Coronary blood flow and cardiac oxygen consumption in unanesthetized dogs. Amer. J. Physiol.,160, 149. 